\title{
JOTSE'S COVID-19 EVOLUTION
}

\section{Beatriz Amante García ${ }^{1}$ (D), María Martínez Martínez ${ }^{2}$ D}

${ }^{1}$ Projectes d'Enginyeria, Universitat Politècnica de Catalunya (Spain)

${ }^{2}$ Enginyeria Química, Universitat Politècnica de Catalunya (Spain)

beatriz.amante@upc.edu,rosario.martinez@upc.edu

We present the first number of the year in JOTSE. As usual, in this first number we present ours editorial with an analysis of our Journal evolution. In this sense, we reflect on the changes just undergone in 2021 with an international pandemic "covid-19" and the challenges to be faced in the New Year 2022.

When analyzing JOTSE's evolution (See Figure 1) we can observe that the objective of growth has been accomplished in this last year with this terrible covid-19 pandemic.

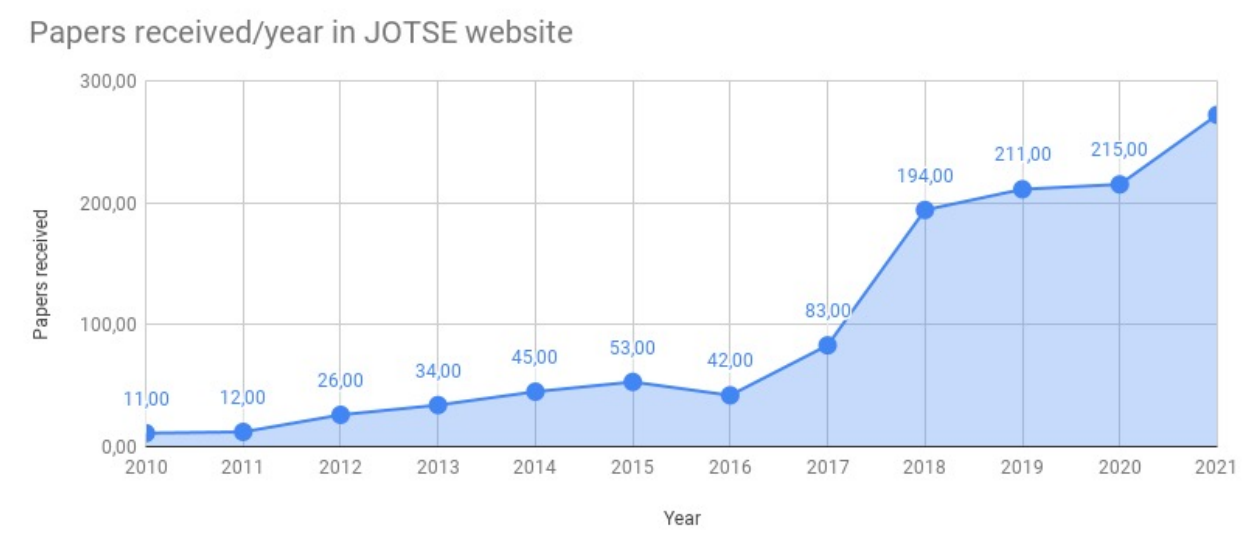

Figure 1. JOTSE's evolution (2010-2021)

As a matter of fact, if we observe JOTSE's monthly evolution we can state that July and December are the months with more papers submissions as the average increases (as shown in Table 1). This 2021 year, was really complicate due to the pandemic COVID-19 and I want to thanks an all colleagues that colaborate with JOTSE because we have had $27 \%$ as much articles than in preceding year. 


\begin{tabular}{|c|c|c|c|c|c|c|c|c|c|c|c|c|}
\hline & $\mathbf{2 0 1 0}$ & $\mathbf{2 0 1 1}$ & $\mathbf{2 0 1 2}$ & $\mathbf{2 0 1 3}$ & $\mathbf{2 0 1 4}$ & $\mathbf{2 0 1 5}$ & $\mathbf{2 0 1 6}$ & $\mathbf{2 0 1 7}$ & $\mathbf{2 0 1 8}$ & $\mathbf{2 0 1 9}$ & $\mathbf{2 0 2 0}$ & $\mathbf{2 0 2 1}$ \\
\hline January & & 0 & 2 & 1 & 9 & 4 & 3 & 2 & 12 & 26 & 13 & 17 \\
\hline February & & 1 & 4 & 1 & 0 & 4 & 1 & 7 & 27 & 15 & 10 & 23 \\
\hline March & & 0 & 1 & 2 & 3 & 5 & 1 & 4 & 11 & 27 & 21 & 22 \\
\hline April & 1 & 1 & 0 & 3 & 2 & 2 & 2 & 0 & 10 & 12 & 17 & 22 \\
\hline May & 3 & 2 & 0 & 0 & 2 & 2 & 3 & 5 & 24 & 13 & 16 & 22 \\
\hline June & 1 & 4 & 0 & 3 & 1 & 4 & 3 & 3 & 11 & 8 & 17 & 23 \\
\hline July & 1 & 0 & 7 & 5 & 8 & 5 & 3 & 2 & 13 & 15 & 22 & 29 \\
\hline August & 1 & 1 & 1 & 2 & 1 & 2 & 2 & 13 & 9 & 12 & 17 & 25 \\
\hline September & 0 & 1 & 3 & 1 & 5 & 5 & 2 & 14 & 32 & 24 & 18 & 12 \\
\hline October & 2 & 0 & 4 & 1 & 1 & 3 & 8 & 8 & 8 & 25 & 16 & 22 \\
\hline November & 1 & 1 & 1 & 6 & 2 & 9 & 11 & 11 & 16 & 14 & 26 & 21 \\
\hline December & 1 & 1 & 3 & 9 & 11 & 8 & 3 & 14 & 21 & 20 & 22 & 34 \\
\hline TOTAL & $\mathbf{1 1}$ & $\mathbf{1 2}$ & $\mathbf{2 6}$ & $\mathbf{3 4}$ & $\mathbf{4 5}$ & $\mathbf{5 3}$ & $\mathbf{4 2}$ & $\mathbf{8 3}$ & $\mathbf{1 9 4}$ & $\mathbf{2 1 1}$ & $\mathbf{2 1 5}$ & $\mathbf{2 7 2}$ \\
\hline
\end{tabular}

Table 1. Article submissions evolution from 2010 to 2021

When analysing the percentage of rejected articles, we can see in the website of JOTSE, in this year 2021 it was $54,79 \%$ (a little more than before). Although if we have a look in more detail at the numbers, of 275 received, only 74 go through the review process and of these halves are rejected.

These numbers show the level of quality required to publish on JOTSE. It is important to mention here the important role of JOTSE's editorial team and reviewers who do their job with much rigor and generosity. In fact, we could not publish our journal without their help and, therefore, we thank them all to be here.

Now, if we analyze JOTSE's internationalization with the number of visited of JOTSE's website (410,814 visits between November 4th, 2015 to January 20th, 2022), we can observe in the figure 2 the distribution in the wold with Philippines, US, Indonesia and Spain in the first positions.

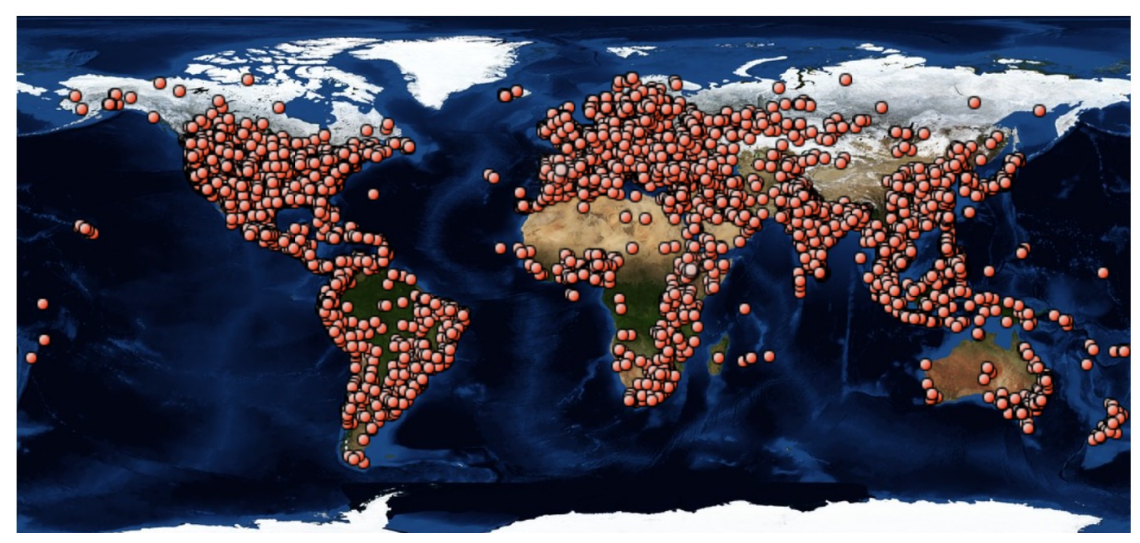

Figure 1. Origin of visitors

The new goal is to publish articles from more different countries and growing with high quality.

Last but not least, we would like to thank to readers and authors for continuing to trust us.

\section{Declaration of Conflicting Interests}

The authors declared no potential conflicts of interest with respect to the research, authorship, and/or publication of this article. 


\section{Funding}

The authors received no financial support for the research, authorship, and/or publication of this article.

\section{To cite this article:}

Amante García, B., \& Martínez Martínez, M (2022). JOTSE’s Covid-19 Evolution. Journal of Technology and Science Education, 12(1), 1-3. https://doi.org/10.3926/jotse.1608

Published by OmniaScience (www.omniascience.com)

Journal of Technology and Science Education, 2022 (www.jotse.org)

\section{(ㄷ) (1) $\Theta$}

Article's contents are provided on an Attribution-Non Commercial 4.0 Creative commons International License. Readers are allowed to copy, distribute and communicate article's contents, provided the author's and JOTSE journal's names are included. It must not be used for commercial purposes. To see the complete licence contents, please visit https://creativecommons.org/licenses/by-nc/4.0/. 